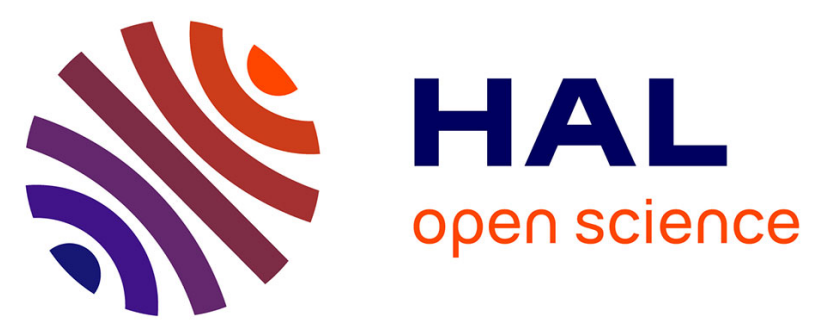

\title{
Lymphatic drainage in the muscle and subcutis of the arm after breast cancer treatment
}

Anthony W. B. Stanton, Stephanie Modi, Thomas M. Bennett Britton, Anand

D. Purushotham, A. Michael Peters, J. Rodney Levick, Peter S. Mortimer

\section{To cite this version:}

Anthony W. B. Stanton, Stephanie Modi, Thomas M. Bennett Britton, Anand D. Purushotham, A. Michael Peters, et al.. Lymphatic drainage in the muscle and subcutis of the arm after breast cancer treatment. Breast Cancer Research and Treatment, 2008, 117 (3), pp.549-557. 10.1007/s10549-0080259-z . hal-00535320

\author{
HAL Id: hal-00535320 \\ https://hal.science/hal-00535320
}

Submitted on 11 Nov 2010

HAL is a multi-disciplinary open access archive for the deposit and dissemination of scientific research documents, whether they are published or not. The documents may come from teaching and research institutions in France or abroad, or from public or private research centers.
L'archive ouverte pluridisciplinaire HAL, est destinée au dépôt et à la diffusion de documents scientifiques de niveau recherche, publiés ou non, émanant des établissements d'enseignement et de recherche français ou étrangers, des laboratoires publics ou privés. 


\title{
Lymphatic drainage in the muscle and subcutis of the arm after breast cancer treatment
}

\author{
Anthony W. B. Stanton $\cdot$ Stephanie Modi $\cdot$ \\ Thomas M. Bennett Britton - Anand D. Purushotham • \\ A. Michael Peters $\cdot$ J. Rodney Levick $\cdot$ Peter S. Mortimer
}

Received: 5 September 2008/Accepted: 17 November 2008/Published online: 4 December 2008

(C) Springer Science+Business Media, LLC. 2008

\begin{abstract}
Breast cancer-related lymphoedema of the arm (BCRL) results from impaired lymph drainage after axillary surgery. Little is known about lymphatic changes in the arm between surgery and oedema onset. We measured forearm muscle and subcutis lymph drainage in 36 women at 7 and 30 months after surgery by quantitative lymphoscintigraphy. None had BCRL initially but $19 \%$ had BCRL by 30 months. At 7 months muscle and subcutis drainage in both arms of BCRL-destined women exceeded that of non-BCRL women $(P<0.01)$. Muscle lymph drainage always exceeded subcutis drainage $(P<0.0001)$. Muscle
\end{abstract}

A. W. B. Stanton $(\varangle)$ - S. Modi · P. S. Mortimer

Cardiac \& Vascular Sciences (Dermatology), St George's

Hospital Medical School, University of London,

Cranmer Terrace, London SW17 0RE, UK

e-mail: astanton@sgul.ac.uk

T. M. Bennett Britton

Cambridge Breast Unit, Addenbrooke's Hospital,

Cambridge CB2 2QQ, UK

\section{A. D. Purushotham}

Hedley Atkins Breast Unit, Academic Oncology,

Guy's and St Thomas' Trust, London SE1 9RT, UK

A. D. Purushotham

King's College London, London WC2R 2LS, UK

A. M. Peters

Nuclear Medicine, Royal Sussex County Hospital,

Brighton BN2 5BE, UK

J. R. Levick

Basic Medical Sciences (Physiology), St George's Hospital

Medical School, University of London, London SW17 ORE, UK

P. S. Mortimer

Skin and Rare Cancers, Royal Marsden Hospital,

Sutton SM2 5PT, UK lymph drainage in the ipsilateral arm was unimpaired relative to the contralateral arm. BCRL therefore developed in women with higher peripheral lymph flows. The major lymphatic load was generated by muscle; there was no preBCRL lymphatic impairment in the muscle of the ipsilateral arm. We propose that some women have a defined, constitutive predisposition to secondary lymphoedema. Specifically, women with higher filtration rates, and therefore higher lymph flows through the axilla that are closer to the maximum sustainable, are at greater risk of BCRL following axillary trauma, even following removal of 1-2 nodes.

Keywords Arm - Breast cancer - Lymphatic . Lymphoedema $\cdot$ Lymphoscintigraphy $\cdot$ Lymph flow

\section{Introduction}

Axillary nodal surgery and radiotherapy for breast cancer interfere with lymph drainage from the ipsilateral arm. In $21-33 \%$ of women this results in a swelling of the arm, breast cancer-related lymphoedema (BCRL), after a delay of months to years [1-5]. BCRL is associated with pain, impaired function, psychological morbidity, cellulitis, occasionally skin malignancy, and remains a significant clinical problem. There is a perception that the introduction of breast-conserving surgery, and sentinel lymph node biopsy (SLNB) in particular, has made BCRL a thing of the past but the evidence does not support this. After SLNB alone the incidence is 5-7\% [6-8] but the incidence is almost certainly higher in patients in whom more than one axillary node is removed or in whom a double procedure (positive SLNB followed by axillary clearance) is performed. 
The understanding of the pathophysiology of BCRL was limited by technical difficulties in assessing human lymphatic function. In long-established lymphoedema, radiocontrast lymphangiography demonstrated dilated and tortuous lymphatics, dermal backflow and extravasation of contrast medium [9]. These changes were attributed to axillary obstruction because the epifascial vessels (draining skin and subcutis) run mainly to the axilla, although some also anastomose with a scapular collateral pathway [10], and the subfascial (muscle) vessels drain exclusively to the axilla. The epifascial and subfascial compartments communicate at the wrist and elbow [10, 11]. Most swelling is epifascial, particularly in the highly compliant subcutis $[12,13]$. Subfascially, swelling is limited by the tight enveloping fascia, but the volume of fluid presented to the lymphatics each minute may be higher than in the subcutis due to the higher density of filtering capillaries in skeletal muscle. Supporting this view, estimated lymph flow from muscle [14] exceeds that from subcutis [15-17].

Peripheral lymph flow is assessed best by quantitative lymphoscintigraphy (QL) in which the fractional removal rate, $k$, of an injected radiolabelled macromolecule is measured, representing local lymph drainage rate per unit volume of tissue fluid [18]. In the subcutis of the swollen forearm, local lymph drainage is markedly reduced relative to the contralateral arm $[15,16]$. Lymph drainage is also reduced in the forearm muscle, by $31 \%$ in arms with $33 \%$ swelling [14]. There is a graded relation between reduction in muscle lymph drainage and severity of the swelling, but not between reduction in subcutis lymph drainage and swelling [14-16]. Lymphatic function in muscle and subcutis has not to date been compared in the same patients, and little is known of lymphatic function before overt oedema. Investigation of the hand subcutis 3 months after axillary surgery (with no oedema) showed no local impairment of lymph drainage [19]. Declining muscle lymphatic function may be crucial to the pathogenesis of BCRL, and we considered that muscle lymphatic failure might precede onset of oedema. We therefore measured lymph flow in the forearm muscle and subcutis of women treated recently by axillary surgery, initially without BCRL, and repeated the measurements $2 \frac{1}{2}$ years later by which time some had developed BCRL.

\section{Patients and methods}

Patients and assessment of arms

Forty-three breast cancer patients from St George's Hospital, London, the Royal Marsden Hospital, Sutton, and Addenbrooke's Hospital, Cambridge, were assessed $7.3 \pm 2.8$ months (mean $\pm \mathrm{SD}$ ) after surgery. Seven of the
$43(16 \%)$ were found to have signs of (previously undiagnosed) incipient arm oedema (see below) and were therefore excluded, leaving 36 women aged $61 \pm 9$ years (range: 46-81 years) of body mass index (BMI) $25.9 \pm$ $3.8 \mathrm{~kg} / \mathrm{m}^{2}$ without detectable BCRL for this study. All patients had undergone standard axillary nodal surgery (mainly level I + II); none received axillary radiotherapy. No patient had other serious disease or was on $\mathrm{Ca}^{2+}$. channel blockers or developed cancer recurrence during the study. All were right-handed.

The diagnosis of BCRL in the excluded patients and in the patients who later developed BCRL was based on examination for the clinical signs of oedema, rather than arm volume alone [20]. BCRL was considered to be present in the ipsilateral arm if (1) the subcutaneous veins of the ventral forearm and dorsal hand were less visible than on the contralateral side; (2) there was a rounding or fullness in the medial elbow and distal upper arm regions; (3) skin and subcutis thickness was increased; (4) pitting oedema was present. Arm volumes were measured using a Perometer 350S limb volumeter (Pero-System, Wuppertal, Germany) in 26 patients, and a tape-measure (with calculation of arm volume from serial circumferences measured at $4 \mathrm{~cm}$ intervals) in the remaining 10 [21]. The eventual 7 BCRL patients had had significantly fewer axillary lymph nodes excised than the 29 non-BCRL patients ( $8 \pm 3$ vs. $15 \pm 8, P=0.032$, unpaired $t$ test); the BCRL group was 6 years younger than the non-BCRL group (57.1 \pm 3.3 vs. $63.2 \pm 9.2$ years at 7 months post-surgery, $P=0.10)$, had smaller primary tumours $(17 \pm 7$ vs. $23 \pm 10 \mathrm{~mm}$, $P=0.13$ ), and had received a smaller proportion of mastectomies (14 vs. $21 \%$ ) as opposed to wide local excisions. Every BCRL patient and 21/29 non-BCRL patients received breast/chest wall radiotherapy, which may increase the risk of BCRL [5]. The BMI of the BCRL and the non-BCRL groups was almost identical $(P=0.77)$.

The study was approved by the Research Ethics Committees, conformed to the Declaration of Helsinki, and was approved by the Administration of Radioactive Substances Advisory Committee, UK (ARSAC). The effective radiation dose was $\sim 0.04 \mathrm{mSv}$ per patient. All participants gave informed, written consent.

Quantitative lymphoscintigraphy and time course of studies

QL was performed on the forearm in order to measure $k$ (local lymph flow/volume of distribution of tracer). The radiopharmaceutical was human IgG (TechneScan HIG, DRN 4369; Mallinckrodt, Petten, Netherlands) labelled with ${ }^{99 \mathrm{~m}_{\mathrm{Tc}}}$ ( $\left.{ }^{99 \mathrm{~m}} \mathrm{Tc}-\mathrm{HIG}\right)$. Radiochemical purity was $99.1 \%$. The scintillation detectors (Ametek, Wokingham, UK) were calibrated for the pulse energy of ${ }^{99 \mathrm{~m}} \mathrm{Tc}(137-143 \mathrm{keV}) . \mathrm{QL}$ 
and the theory equating $k$ to lymph drainage have been described in detail and reviewed critically [14-18, 22]. The patients underwent 4 bilateral QL studies; study 1 (at 7.3 months post-surgery): $k$ in the subcutis, study 2 (within 7 days of study 1): $k$ in the muscle, studies 3 and 4 (at $30.5 \pm$ 4.0 months): repetition of studies 1 and 2 . At 30 months the arms were assessed again for clinical signs of oedema.

After $45 \mathrm{~min}$ acclimatisation at $23 \pm 1^{\circ} \mathrm{C}$ the forearms were supported at heart level and an injection point marked on each ventral forearm at $390 \pm 20 \mathrm{~mm}$ from the middle fingertip and $60 \pm 10 \mathrm{~mm}$ lateral to the midline. ${ }^{99 \mathrm{~m}} \mathrm{Tc}-\mathrm{HIG}$ $(0.2 \mathrm{ml}, 0.60 \pm 0.08 \mathrm{MBq})$ was injected subcutaneously for studies 1 and 3 or intramuscularly for studies 2 and 4 . The scintillation detectors were positioned $\sim 1 \mathrm{~mm}$ above the skin over each depot. The maximum depot diameter, $31 \mathrm{~mm}$, was $<50 \%$ of the diameter of the skin area under the detector (65 mm) [15]. Acquisitions (duration 100s) were performed every $15 \mathrm{~min}$ for $3 \mathrm{~h}$. During the intervening periods the patient mostly sat but was also allowed to walk short distances. The arms and detectors were carefully repositioned for each acquisition.

\section{Calculation of $k$}

Counts were corrected for background and radioactive decay, according to $N=N_{0} \mathrm{e}^{-\gamma t}$ ( $N$ corrected counts, $N_{0}$ uncorrected counts, $\gamma$ decay constant $(0.001923 / \mathrm{min}), t \mathrm{~min}$ since injection). The counts remaining in the depot were then expressed as the fraction of the counts from the first acquisition, and the slope of the $\log _{e}$ of the fraction versus time plot $(\times 100)$ gave the percentage of the depot cleared per minute, $k(\% / \mathrm{min})$. The slope was measured from the end of any initial lag phase (28-30\% of cases, duration $\sim 30 \mathrm{~min}$ ).

\section{Statistical analysis}

Results are shown as the mean \pm standard deviation (SD), with the range for some results, and the standard error of the mean (SEM) in the figures. Groups were compared using Student's unpaired and paired $t$ tests, Wilcoxon's matched pairs test for non-Gaussian ratios of subcutis $k$ to muscle $k$, and 2-way analysis of variance (ANOVA). The slope of the depot clearance plot was obtained by linear regression. Analysis was performed using Prism 4.0 (GraphPad, San Diego, CA). Significance was accepted at $P<0.05$.

\section{Results}

Compliance, incidence of BCRL and arm volumes

Thirty-six women completed studies 1-2, 33 completed studies 1-3 and 32 completed studies $1-4$. Arm volumes at
7 months for the whole group were similar on the ipsilateral and contralateral sides $(n=36)$ (Table 1$)$. Six patients were diagnosed with BCRL at $19 \pm 5$ months (11-23 months) after surgery. One further patient was found to have previously unrecognised clinical signs of oedema at study 3, giving an overall incidence of BCRL from 7 to 30 months of $19 \%$. Including the rejected incipient cases, the incidence (from 2 months) was 14/43 (32.5\%).

At 30 months the lymphoedematous arm was $5.8 \pm 2.0 \%$ bigger than the contralateral $\operatorname{arm}(n=7, P=0.0007$, paired $t$ test) (Table 1). The difference in arm volume was due partly to ipsilateral swelling and partly to a $2.2 \pm 2.5 \%$ fall in contralateral arm volume $(P=0.091)$ (Table 1$)$. The arms of the patients who did not develop BCRL changed little in volume.

Lymph drainage rates 7 months after axillary surgery

Three findings emerged from studies 1-2.

(1) $k$ in the muscle was consistently greater than in the subcutis of the same arm, exceeding subcutis $k$ in $69 / 72$ arms ( $P \ll 0.0001$, paired $t$ test) (Table 2; Fig. 1, panel a). The ratio muscle $k$ /subcutis $k$ was $2.1 \pm 0.9$ in the ipsilateral arm and $2.2 \pm 1.1$ in the contralateral arm $(n=36)$. The absolute value of muscle $k, 0.15 \% / \mathrm{min}$ (Table 2), showed that $\sim 9 \%$ of the muscle interstitial fluid is drained by the lymphatics and replaced by capillary ultrafiltrate per $\mathrm{h}$. The entire interstitial fluid volume of muscle thus turns over in $\sim 11 \mathrm{~h}$. The turnover time for subcutis ( $k=0.077 \% / \mathrm{min}$; Table 2$)$ is much slower, $\sim 22 \mathrm{~h}$.

(2) Lymph drainage in the subcutis and muscle of the ipsilateral arm was the same as in the contralateral arm ( $n=36$ ) (Fig. 1, panel b). This indicated that surgery had not in general caused any chronic deterioration of peripheral lymph flow by 7 months. Similarly, in the 7 women destined to develop BCRL, muscle $k$ in the ipsilateral arm $(0.171 \pm 0.054 \% / \mathrm{min})$ was not significantly lower than in the contralateral arm $(0.188 \pm 0.089 \% / \mathrm{min}, P=0.72$, paired $t$ test), although the $15 \%$ lower $k$ in the subcutis of the ipsilateral arm approached statistical significance $(P=0.085)$ (Table 2).

(3) Unexpectedly, the drainage rate constants were higher in both the ipsilateral and contralateral arms of the BCRL-destined patients, with as yet no oedema, than in the non-BCRL subgroup (Fig. 2). The difference was substantial and was seen consistently in both the subcutis and the muscle, and in both the ipsilateral and the contralateral arms (Table 2). Ipsilateral and contralateral muscle $k$ values were, respectively 22 and $29 \%$ higher in the BCRL than in non-BCRL subgroup $(P=0.007 ; P=0.4$ for comparison of arms, 2-way ANOVA). Similarly, ipsilateral and contralateral subcutis $k$ values were 22 and $50 \%$ higher 
Table 1 Arm volumes $(\mathrm{ml})$ following axillary surgery (mean \pm SD)

\begin{tabular}{|c|c|c|c|c|c|c|}
\hline \multirow{2}{*}{ Subgroup $(n)$} & \multicolumn{3}{|l|}{7 months } & \multicolumn{3}{|l|}{30 months } \\
\hline & Ipsilateral & Contralateral & $P^{\mathrm{a}}$ & Ipsilateral & Contralateral & $P^{\mathrm{a}}$ \\
\hline All cases (36) & $1,917 \pm 360$ & $1,906 \pm 377$ & 0.34 & - & - & - \\
\hline BCRL (7) & $1,935 \pm 367^{\mathrm{b}}$ & $1,893 \pm 325$ & 0.081 & $1,958 \pm 347$ & $1,851 \pm 320$ & 0.001 \\
\hline Non-BCRL ${ }^{c}$ & $1,913 \pm 365$ & $1,909 \pm 394$ & 0.79 & $1,895 \pm 375$ & $1,899 \pm 361$ & 0.81 \\
\hline
\end{tabular}

Lymphoedema was absent at 7 months but had developed in the ipsilateral arms of the BCRL subgroup by 30 months

a Ipsilateral versus contralateral arms, paired $t$ test

b $2.0 \%$ bigger than the contralateral arm (5/7 arms were on the dominant side)

c $n=29$ at 7 months, $n=26$ at 30 months; for the 25 women who completed all 4 studies to 30 months, at 7 months ipsilateral arm volume was $1,915 \pm 377 \mathrm{ml}$ and contralateral arm volume was $1,916 \pm 409 \mathrm{ml}$

Table 2 Arm lymph drainage rates, represented by the removal rate constant for ${ }^{99 \mathrm{~m}} \mathrm{Tc}-\mathrm{HIG}(k, \% / \mathrm{min})$, at 7 and 30 months post-axillary surgery (mean $\pm \mathrm{SD}$, negative sign of $k$ omitted)

\begin{tabular}{|c|c|c|c|c|c|c|}
\hline & \multicolumn{3}{|l|}{7 months } & \multicolumn{3}{|l|}{30 months } \\
\hline & Ipsilateral & Contralateral & $P^{\mathrm{a}}$ & Ipsilateral & Contralateral & $P^{\mathrm{a}}$ \\
\hline \multicolumn{7}{|c|}{ All cases $(n=36)$} \\
\hline Subcutis & $0.077 \pm 0.023$ & $0.077 \pm 0.028$ & 0.93 & - & - & - \\
\hline Muscle & $0.147 \pm 0.032$ & $0.154 \pm 0.055$ & 0.48 & - & - & - \\
\hline$P^{\mathrm{b}}$ & $<0.0001$ & $<0.0001$ & & - & - & - \\
\hline \multicolumn{7}{|c|}{ BCRL subgroup $(n=7)$} \\
\hline Subcutis & $0.090 \pm 0.026$ & $0.106 \pm 0.036$ & 0.085 & $0.074 \pm 0.031$ & $0.078 \pm 0.017$ & 0.67 \\
\hline Muscle & $0.171 \pm 0.054$ & $0.188 \pm 0.089$ & 0.72 & $0.227 \pm 0.082$ & $0.215 \pm 0.055$ & 0.75 \\
\hline \multicolumn{7}{|c|}{ Non-BCRL subgroup ${ }^{c}$} \\
\hline Subcutis & $0.074 \pm 0.021$ & $0.070 \pm 0.021$ & 0.32 & $0.083 \pm 0.030$ & $0.083 \pm 0.029$ & 0.91 \\
\hline Muscle & $0.141 \pm 0.022$ & $0.146 \pm 0.041$ & 0.50 & $0.170 \pm 0.044$ & $0.180 \pm 0.041$ & 0.18 \\
\hline
\end{tabular}

${ }^{a}$ Ipsilateral versus contralateral arms

b Subcutis versus muscle, paired $t$ tests

c $n=29$ at 7 months, $n=26$ (subcutis) and $n=25$ (muscle) at 30 months; for the 25 women who completed all 4 studies to 30 months, at 7 months subcutis $k$ was-ipsilateral: $0.074 \pm 0.022 \% / \mathrm{min}$, contralateral: $0.072 \pm 0.022 \% / \mathrm{min}$, and muscle $k$ was-ipsilateral: $0.140 \pm 0.023 \% / \mathrm{min}$, contralateral: $0.143 \pm 0.042 \% / \mathrm{min}$

in the pre-BCRL patients than in the non-BCRL subgroup $(P=0.002 ; P=0.4$ for arms).

Change in lymph drainage rates in the BCRL subgroup from 7 to 30 months

Seven women developed mild ipsilateral BCRL by 30 months. Consistent with previous work $[15,16]$, subcutis $k$ fell by $\sim 18 \%$ in the lymphoedematous arm relative to its value at 7 months (Fig. 3, panel a). Contrary to expectation, subcutis $k$ declined also in the contralateral arm of the BCRL patients. As a result the subcutis $k$ was only slightly lower in the lymphoedematous arm than in the opposite arm $(P=0.67$ for difference between arms) (Table 2$)$. Two-way ANOVA showed that the fall in $k$ with time was statistically significant $(P=0.020)$ while the difference between arms was not $(P=0.45)$. The deterioration in subcutis $k$ (the difference between $k$ at 7 and 30 months) did not correlate with patient age.

Muscle $k$ showed no significant difference between the two arms at 30 months $(P=0.75)$ (Table 2$)$. In contrast with the deterioration in subcutis $k$ over time, muscle $k$ did not fall between 7 and 30 months (Fig. 3, panel b). Instead it tended to increase in both arms, although this did not reach conventional significance $(P=0.11,2$-way ANOVA). The magnitude of the changes in muscle or subcutis $k$ did not correlate significantly with the magnitude of the swelling. Since subcutis $k$ fell while muscle $k$ increased, the subcutis/muscle ratio fell markedly, namely by $34 \%$ in the lymphoedematous arm, from $0.57 \pm 0.24$ at 7 months to $0.35 \pm 0.17$ at 30 months $(P=0.016$, Wilcoxon test) (Fig. 4, left panel). In the contralateral arm the ratio fell by $28 \%$, from $0.68 \pm 0.39$ at 7 months to $0.39 \pm 0.12$ at 30 months $(P=0.047)$. 
Fig. 1 High muscle lymph flow and unimpaired ipsilateral drainage rates $(k)$ in 36 postoperative patients without BCRL at 7 months postsurgery. a Individual $k$ values from all ipsilateral and contralateral arms, with lines connecting muscle and subcutis $k$ in same arm; muscle $k$ was 2-3 times subcutis $k(n=72$ arms, $P<0.0001)$. b Individual $k$ values from the muscle and subcutis of each arm, with the mean and SD (thick and thin horizontal lines, respectively); $k$ in the ipsilateral arm did not differ significantly from $k$ in the contralateral arm in either compartment $(P$-values, paired $t$ tests)

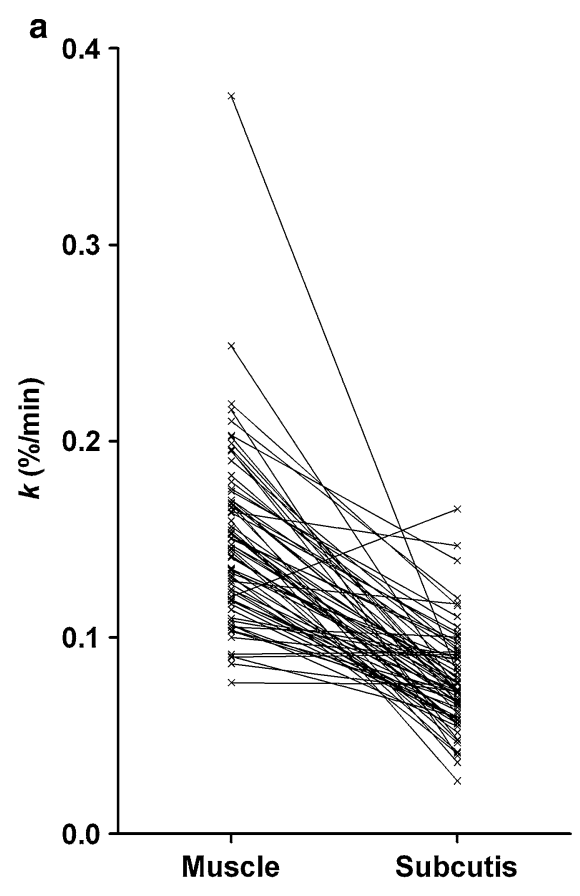

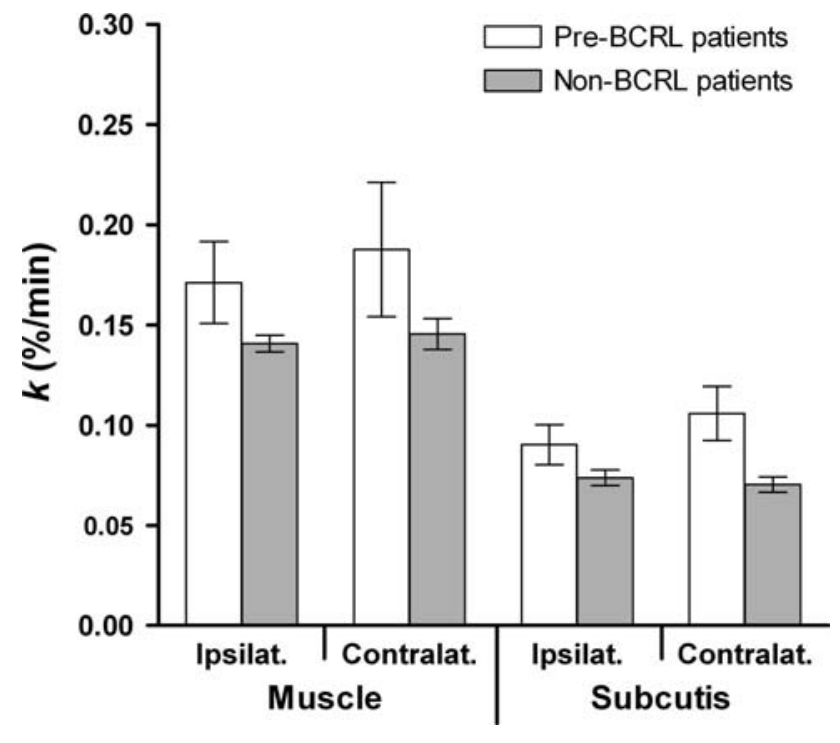

Fig. 2 High fluid turnover rates in patients with latent BCRL at 7 months post-surgery. Lymph drainage rate constants $(k$, mean \pm SEM) in the subcutis and muscle of both arms were higher in the women destined to develop BCRL in $\sim 12$ months time (pre-BCRL, $n=7$ ) (open columns) than in the women would not develop BCRL (non-BCRL, $\quad n=25-29, \quad P<0.01, \quad 2$-way ANOVA) (shaded columns)

Change in lymph drainage rates in the non-BCRL subgroup from 7 to 30 months

In the $81 \%$ of women spared of BCRL the pattern of change was different from that in the BCRL group, in that $k$ increased in both the subcutis and muscle between

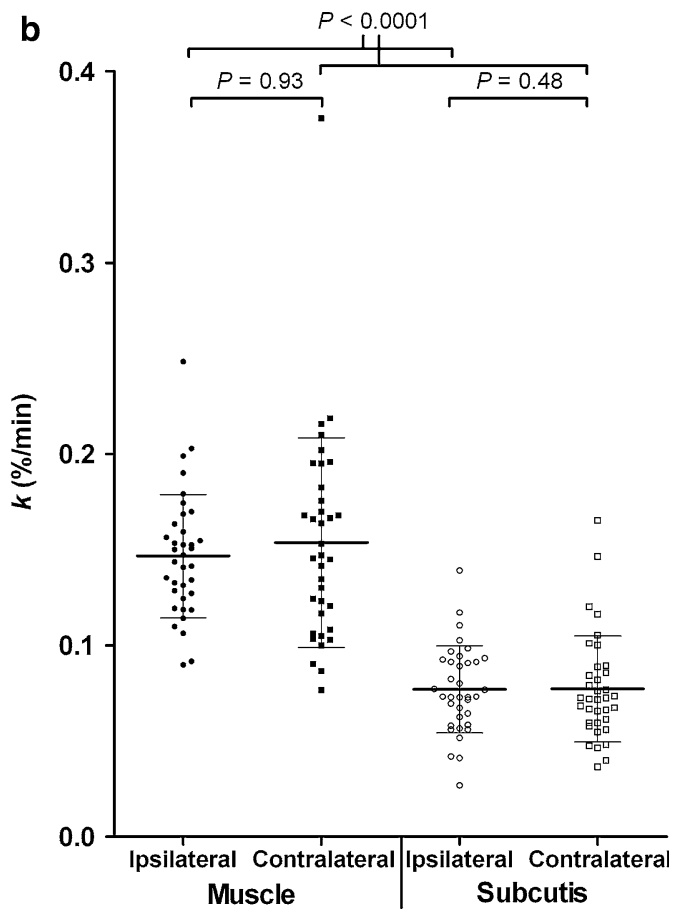

7 months and 30 months (Fig. 3, panel b). Subcutis $k$ increased by $18 \pm 38 \%$ ipsilaterally and $16 \pm 30 \%$ contralaterally $(n=26, P=0.048,2$-way ANOVA). Muscle $k$ likewise increased, by $24 \pm 37 \%$ ipsilaterally and $36 \pm 47 \%$ contralaterally $(n=25, P<0.0001)$. The arms did not differ significantly $(P \geq 0.3)$. These changes showed no correlation with age.

Since $k$ increased in both the subcutis and muscle, their ratio changed little. In the ipsilateral arm the mean ratio was $0.54 \pm 18$ at 7 months and $0.54 \pm 0.26$ at 30 months ( $n=25, P=0.78$, Wilcoxon test). Contralaterally the ratio was $0.52 \pm 0.21$ at 7 months and $0.49 \pm 0.21$ at 30 months $(n=25, P=0.059)$ (Fig. 4, right panel). This contrasted markedly with the lymphoedematous arms, in which the subcutis/muscle ratio fell by $28-34 \%$ (Fig. 4, left panel).

As at 7 months, muscle $k$ in the BCRL group at 30 months exceeded that in the non-BCRL group, by $34 \%$ in the ipsilateral arm and $19 \%$ in the contralateral arm ( $n=7$ and $25, P=0.002$ for difference between groups, 2-way ANOVA) (Table 2). Subcutis $k$ in the BCRL group at 30 months no longer exceeded that in the non-BCRL group because it had fallen bilaterally.

\section{Discussion}

This study demonstrates that the traditional view of BCRL as an obstructive lymphoedema caused by axillary surgery is too simplistic. There was no deterioration in muscle or 


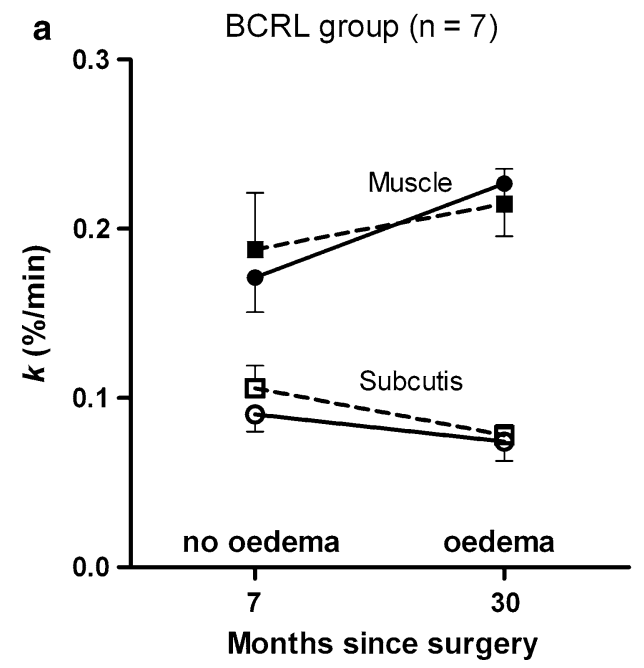

Fig. 3 Changes in lymph removal rate constant $(k)$ from 7 to 30 months post-surgery (mean $\pm \mathrm{SEM}$; filled symbols, muscle $k$; open symbols, subcutis $k$ ). a The BCRL group developed ipsilateral lymphoedema by 30 months. The ipsilateral arm showed a fall in subcutis $k$ but not muscle $k$, with similar changes in the contralateral

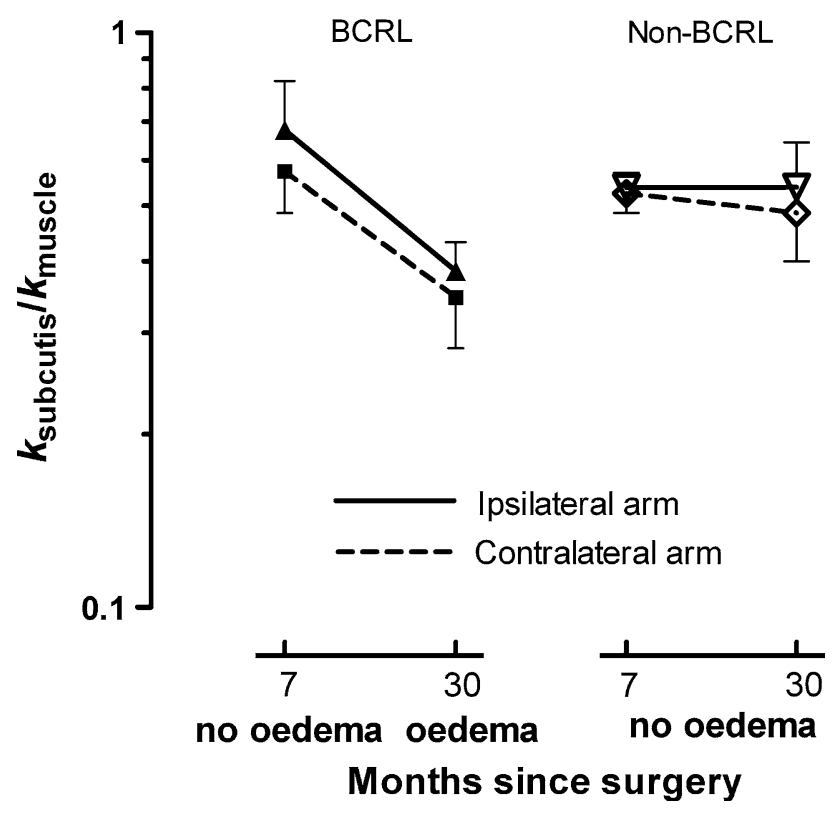

Fig. 4 Ratio of lymph removal rate constant in subcutis to that in muscle $\left(k_{\text {subcutis }} / k_{\text {muscle }}\right.$, mean $\left.\pm \mathrm{SEM}\right)$ for the ipsilateral and contralateral arms of women who develop BCRL (left panel, filled symbols) and for those who do not develop BCRL (right panel, open symbols) at 7 and 30 months post-surgery. $k_{\text {subcutis }} / k_{\text {muscle }}$ decreased in both arms of the BCRL group from 7 to 30 months $(n=7, P<0.05$, Wilcoxon test) whereas changes in the non-BCRL group were small. Logarithmic ordinate to normalise ratio distribution

subcutis lymph flow at 7 months, in either the entire group or the subgroup that progressed to BCRL. There was therefore no support for the hypothesis of muscle lymphatic impairment during the pre-oedema phase. Muscle

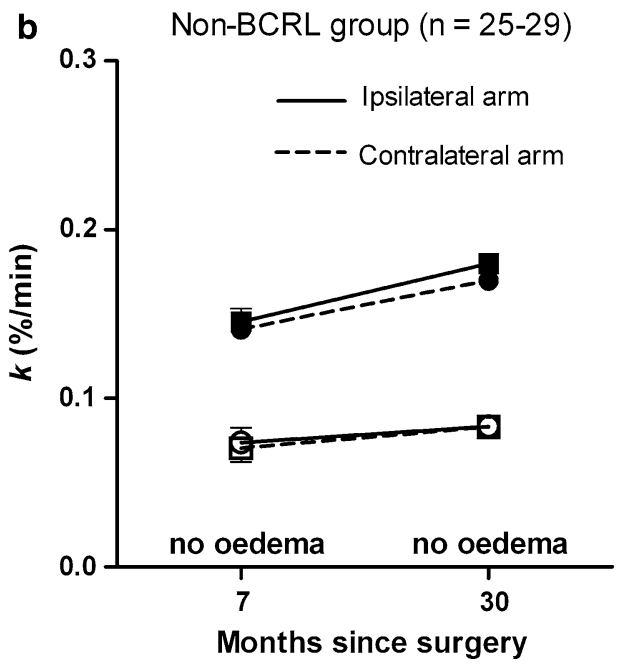

arm. b Women who did not develop BCRL (non-BCRL group) showed a bilateral rise in subcutis and muscle $k$, similar to the bilateral increase in muscle $k$ in the BCRL patients. The distinguishing feature of the BCRL group was thus a bilateral fall in subcutis $k$

lymph flow at 7 months was actually higher in both arms of women who progressed to BCRL than in those who did not. Since lymph production is coupled closely to capillary filtration ( $k$ reflects lymph production as well as flow), it is likely that the women who progress to BCRL have greater filtration into the arm that overwhelms vulnerable lymphatics. We propose therefore that the first abnormality to develop in the pathogenesis of BCRL is not lymphatic obstruction but high fluid filtration into both arms with subsequent lymphatic failure and the development of oedema.

\section{Incidence of BCRL and risk factors}

The incidence of BCRL following standard axillary nodal surgery (19\% at $7-30$ months, $32.5 \%$ including the incipient cases) is consistent with previous studies [2-5]. The reported frequency of BCRL among women treated for breast cancer varies because of differing definitions of BCRL and differing follow-up periods. In the present study arms were examined using strict clinical criteria for oedema and diagnosis was not based on arbitrary circumference or volume thresholds that may not detect mild cases [20]. Approximately $75 \%$ of cases of BCRL develop within 2 years of treatment and 90\% within 3 years [23], so most expected cases from the original cohort of 43 were manifest. The BCRL group differed from the non-BCRL group somewhat, in particular the fewer lymph nodes removed, which might have been expected to reduce the risk of BCRL, with statistically weaker differences in age and size of breast tumour. 
Muscle versus subcutis fluid turnover

Muscle $k$ was consistently $\sim 2-3$ times higher than subcutis $k$ in the same arm, in agreement with earlier indications from separate patient groups $[14,15]$. This indicates that interstitial fluid drainage into the microlymphatic system is 2-3 times faster in muscle than subcutis. Since the rate of lymph and interstitial fluid formation is closely coupled to capillary filtration rate in the steady state $[24,25]$, the findings indicate a faster generation of interstitial fluid by capillary filtration in muscle. While differences in the Starling forces may contribute to this, the most obvious explanation is that the numerical density of blood capillaries in skeletal muscle $\left(300-1,000 / \mathrm{mm}^{2}\right)$ is $\sim 3$ times that in adipose subcutis [26-28]. The difference in $k$ and the greater mass of muscle indicates that the subfascial compartment generates most of the lymphatic 'load' (volume per unit time) reaching the axilla.

High-filtering patients susceptible to lymphoedema

At 7 months the peripheral lymph flow in the muscle and subcutis of both arms was significantly higher in the preBCRL women than the non-BCRL women (Fig. 2). Muscle lymph flow was likewise higher in the BCRL women than controls at 30 months (Table 2). The coupling of lymph flow and capillary filtration rate $\left(J_{\mathrm{v}}\right)$ leads us to infer the existence of a subgroup of 'high-filtering' breast cancer patients at increased risk of BCRL.

There are two possible mechanisms whereby a higher lymph load might contribute to the onset of lymphoedema. First, lymph transport by lymphatic trunk vessels involves an active contractile process and is subject to overload failure $[24,29]$. The high volume load discovered here may therefore be a factor leading to eventual chronic failure. Second, if lymphatic contractility decreases for any reason, the consequences for tissue fluid balance will be worst in individuals that present the greatest volume of lymph for transport.

Direct evidence for a constitutively raised $J_{\mathrm{v}}$ in BCRL is lacking, but earlier QL findings from hand subcutis in BCRL patients with and without hand swelling are compatible with this. In women with swelling involving the hand, lymph flow in the contralateral, unaffected hand was higher than in the swollen hand and higher than in either hand of women without hand involvement [17]. This is compatible with a constitutive higher filtration state in more severely affected patients. Furthermore, the contralateral dermal microlymphatics of BCRL patients are wider than in non-BCRL breast cancer patients, pointing again to a constitutive difference [30]. $J_{\mathrm{v}}$ has been measured for the whole forearm (skin, subcutis and muscle) by venous occlusion plethysmography and was similar in the swollen and contralateral arms in long-established BCRL [31]; $J_{\mathrm{v}}$ has not been measured in the latent phase in pre-BCRL patients relative to non-BCRL patients.

What factor(s) might raise $J_{\mathrm{v}}$ ? Decreased tone of resistance vessels would increase capillary pressure and hence $J_{\mathrm{v}}$, but no impairment of sympathetic vasoconstrictor or vasodilator control was detected in BCRL [32]. Angiogenesis could raise blood flow, capillary surface area and filtration rate, but there has been no comparison of these parameters between latent pre-BCRL patients and nonBCRL patients. The total number of capillaries increases in the expanded skin of the lymphoedematous arm, which would increase fluid turnover [33, 34].

A working hypothesis

The new results, combined with those from studies at 92-97 months post-surgery [14, 15], provide a novel, reasonably complete natural history of BCRL (Fig. 5). Both arms of the BCRL patients evinced a fall in subcutis $k$ in association with mild, early lymphoedema. Since $k$ deteriorated bilaterally, it appears to be constitutive in nature, or possibly a systemic effect of cancer treatment. The absence of deterioration in muscle $k$ at this time may be due to early, mild nature of the lymphoedema (muscle $k$ is markedly depressed in long-standing BCRL), and the rise in muscle $k$ contralaterally (Fig. 5) may be the result of improvement in health and physical exercise.

Previous QL studies investigating more severe BCRL (25-34\% swelling) showed that both subcutis and muscle $k$ eventually become markedly impaired in the swollen arm relative to the contralateral arm, the deterioration being greater in muscle [14, 15] (Fig. 5). This appears to offer a rational explanation for the severe oedema. Early, mild swelling was associated with a bilateral fall in subcutis $k$, while the more severe, late swelling was associated with a large fall in muscle $k$. The lower $k$ values in severe swelling indicate a relative stagnation of the interstitial fluid, its turnover time rising to $18 \mathrm{~h}$ in muscle (cf. $11 \mathrm{~h}$ at 7 months) and $24 \mathrm{~h}$ in subcutis. In the present, mild cases, where there was no clear difference in $k$ between the two arms, the oedema may have formed on the treated side due to upstream pump failure between 7 and 30 months, and a constitutive, bilateral fall in fluid turnover may have obscured a small difference between arms.

We propose the following working hypothesis. The primary surgical injury to the lymph nodes increases the resistance to lymph flow in all women [35]. In high-filtering women with a high lymphatic load, the chronically raised afterload eventually impairs lymphatic smooth muscle contractility [29]. Just as in heart failure, the 'backward failure' of the lymphatic pump raises the lymphatic filling pressure, i.e. interstitial fluid pressure [36, 37]. This can 


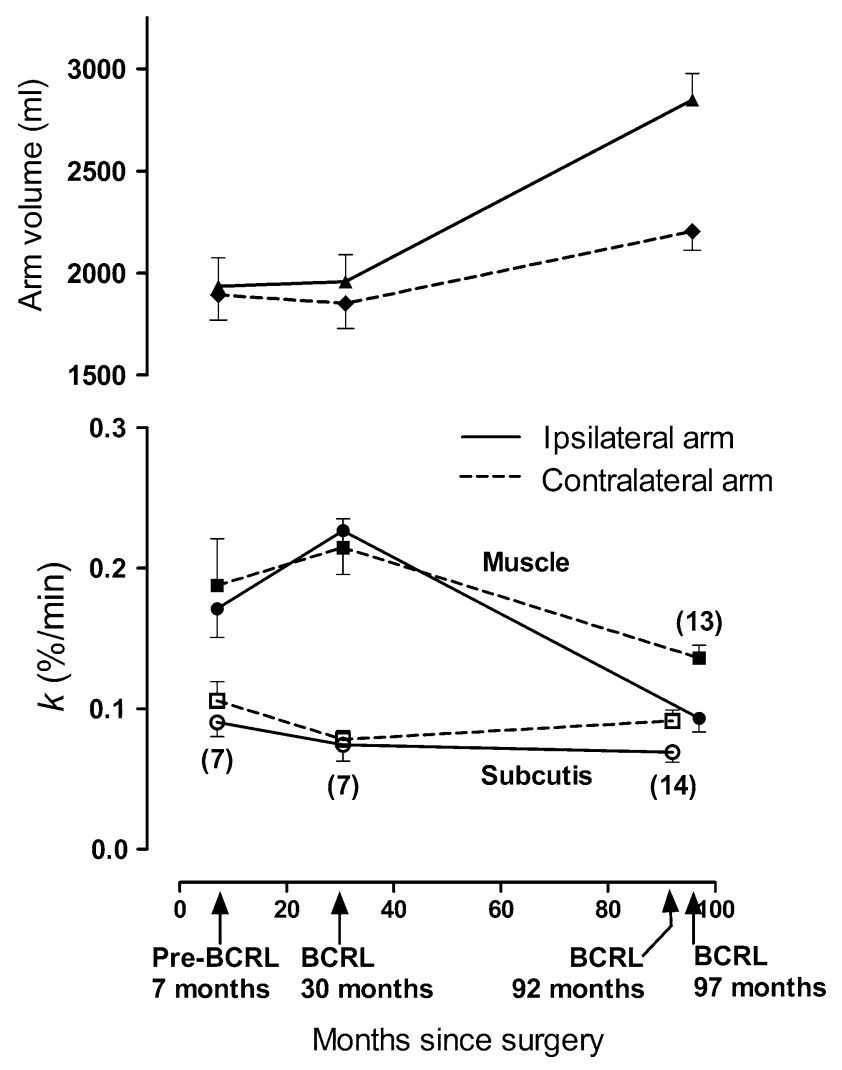

Fig. 5 Time course of changes in arm volume (upper panel) and changes in peripheral lymph drainage ( $k$, lower panel) as BCRL develops over 8 years (mean \pm SEM, $n$ in brackets; lower panel: filled symbols, muscle $k$; open symbols, subcutis $k$ ). Composite plot based on the present results and previous studies of separate patient groups at 92 months (28\% swelling) [15] and 97 months post-surgery (33\% swelling) [14]; arm volumes from previous studies combined $(n=27)$. Early, mild swelling is associated with a bilateral fall in subcutis $k$ whilst later, more severe swelling is associated with a large fall in muscle $k$

help to preserve lymph flow and reduce capillary filtration rate to match the reduced lymph flow [24]. In this way a steady state is reached at an increased limb volume, increased interstitial pressure, and a relatively modest fall in lymph flow.

\section{Conclusion}

The finding of high lymph flows in the muscle and subcutis of both arms of pre-BCRL women leads to the novel hypothesis that patients with constitutively elevated peripheral lymph flows, and by implication capillary filtration rates, form a subgroup predisposed to BCRL after surgery. This could explain why BCRL can develop in women who have had relatively few lymph nodes removed, and raises the possibility of predictive testing for BCRL susceptibility. Support for this hypothesis would come from a prospective study of breast cancer patients from before surgery until such time as BCRL might develop.

Acknowledgments We thank the patients, Mr G. Querci della Rovere (Royal Marsden Hospital, Sutton), Mr A.K. Sharma (St George's Hospital, London) for access to the patients; Dr R. Allan (St George's Hospital) for holding the ARSAC certificate; A. Irwin (St George's Hospital) for physics support; and J. Ballinger (Guy's Hospital, London) and M. Wilkinson (St George's Hospital) for radiopharmacy support. Grant support: We thank the Wellcome Trust (grant number 063025 awarded to P.S. Mortimer) and the Frances and Augustus Newman Foundation (equipment grant).

\section{References}

1. Halsted WS (1921) The swelling of the arm after operations for cancer of the breast-elephantiasis chirurgica-its cause and prevention. Bull Johns Hopkins Hosp 32:309-313

2. Clark B, Sitzia J, Harlow W (2005) Incidence and risk of arm oedema following treatment for breast cancer: a three-year follow-up study. Q J Med 98:343-348

3. Paskett ED, Naughton MJ, McCoy TP et al (2007) The epidemiology of arm and hand swelling in premenopausal breast cancer survivors. Cancer Epidemiol Biomarkers Prev 16:775782. doi:10.1158/1055-9965.EPI-06-0168

4. Querci della Rovere G, Ahmad I, Singh P et al (2003) An audit of the incidence of arm lymphoedema after prophylactic level I/II axillary dissection without division of the pectoralis minor muscle. Ann R Coll Surg Engl 85:158-161. doi:10.1308/ 003588403321661299

5. Hinrichs CS, Watroba NL, Rezaishiraz H et al (2004) Lymphedema secondary to postmastectomy radiation: incidence and risk factors. Ann Surg Oncol 11:573-580. doi:10.1245/ASO.2004. 04.017

6. Blanchard DK, Donohue JH, Reynolds C et al (2003) Relapse and morbidity in patients undergoing sentinel lymph node biopsy alone or with axillary dissection for breast cancer. Arch Surg 138:482-487. doi:10.1001/archsurg.138.5.482

7. Mansel RE, Fallowfield L, Kissin M et al (2006) Randomized multicenter trial of sentinel node biopsy versus standard axillary treatment in operable breast cancer: the ALMANAC trial. J Natl Cancer Inst 98:599-609; erratum: ibid (2006), 98:876

8. Wilke LG, McCall LM, Posther KE et al (2006) Surgical complications associated with sentinel lymph node biopsy: results from a prospective international cooperative group trial. Ann Surg Oncol 13:491-500. doi:10.1245/ASO.2006.05.013

9. Abe R (1976) A study on the pathogenesis of postmastectomy lymphedema. Tohoku J Exp Med 118:163-171

10. Kubik S (1980) The role of the lateral upper arm bundle and the lymphatic watersheds in the formation of collateral pathways in lymphoedema. Acta Biol Acad Sci Hung 31:191-200

11. Gray H (1995) Lymphatic drainage of the upper limbs. In: Williams PL (ed) Gray's anatomy. Churchill Livingstone, Edinburgh, pp 1613-1615

12. Collins CD, Mortimer PS, D'Ettore H et al (1995) Computed tomography in the assessment of response to limb compression in unilateral lymphoedema. Clin Radiol 50:541-544. doi:10.1016/ S0009-9260(05)83188-5

13. Mellor RH, Bush NL, Stanton AWB et al (2004) Dual-frequency ultrasound examination of skin and subcutis thickness in breast cancer-related lymphoedema. Breast J 10:496-503. doi:10.1111/ j.1075-122X.2004.21458.x

14. Stanton AWB, Mellor RH, Cook GJ et al (2003) Impairment of lymph drainage in subfascial compartment of forearm in breast 
cancer-related lymphoedema. Lymphat Res Biol 1:121-132. doi:10.1089/153968503321642615

15. Stanton AWB, Svensson WE, Mellor RH et al (2001) Differences in lymph drainage between swollen and non-swollen regions in arms with breast cancer-related lymphoedema. Clin Sci 101:131140. doi: $10.1042 / C S 20000275$

16. Modi S, Stanton AWB, Mellor RH et al (2005) Regional distribution of epifascial swelling and epifascial lymph drainage rate constants in breast cancer-related lymphoedema. Lymphat Res Biol 3:3-14. doi:10.1089//rb.2005.3.3

17. Stanton AWB, Modi S, Mellor RH et al (2006) A quantitative lymphoscintigraphic evaluation of lymphatic function in the swollen hands of women with lymphoedema following breast cancer treatment. Clin Sci 110:553-561. doi:10.1042/CS2005 0277

18. Modi S, Stanton AWB, Mortimer PS et al (2007) Clinical assessment of human lymph flow using removal rate constants of interstitial macromolecules: a critical review of lymphoscintigraphy. Lymphat Res Biol 5:183-202. doi:10.1089/lrb.2007.5306

19. Pain SJ, Barber RW, Solanki CK et al (2005) Short-term effects of axillary lymph node clearance surgery on lymphatic physiology of the arm in breast cancer. J Appl Physiol 99:2345-2351. doi:10.1152/japplphysiol.00372.2005

20. Stanton A, Modi S, Mellor R et al (2006) Diagnosing cancerrelated lymphoedema in the arm. J Lymphoedema 1:12-15

21. Stanton AWB, Northfield JW, Holroyd B et al (1997) Validation of an optoelectronic limb volumeter (Perometer). Lymphology 30:77-97

22. Levick JR, Mortimer PS (1994) The interpretation of lymphoscintigraphy rate constants. Eur J Lymphol IV:123 letter

23. Rockson SG (2006) Addressing the unmet needs in lymphedema risk management. Lymphat Res Biol 4:42-46. doi:10.1089/ lrb.2006.4.42

24. Levick JR, McHale N (2003) The physiology of lymph production and propulsion. In: Browse N, Burnand K, Mortimer PS (eds) Diseases of the lymphatics. Arnold, London, pp 44-64

25. Mortimer PS, Levick JR (2004) Chronic peripheral oedema: the critical role of the lymphatic system. Clin Med 4:448-453

26. Gersh I, Still MA (1945) Blood vessels in fat tissue. Relation to problems of gas exchange. J Exp Med 81:219-232. doi:10.1084/ jem.81.2.219
27. Honig CR, Frierson JL, Patterson JL (1970) Comparison of neural controls of resistance and capillary density in resting muscle. Am J Physiol 218:937-942

28. Knight AD, Levick JR (1983) The density and distribution of capillaries around a synovial cavity. Q J Exp Physiol 68:629-644

29. Modi S, Stanton AWB, Svensson WE et al (2007) Human lymphatic pumping measured in healthy and lymphoedematous arms by lymphatic congestion lymphoscintigraphy. J Physiol 583(1): 271-285. doi:10.1113/jphysiol.2007.130401

30. Mellor RH, Stanton AWB, Azarbod P et al (2000) Enhanced cutaneous lymphatic network in the forearms of women with postmastectomy oedema. J Vasc Res 37:501-512. doi:10.1159/ 000054083

31. Stanton AWB, Holroyd B, Mortimer PS et al (1999) Comparison of microvascular filtration in human arms with and without postmastectomy oedema. Exp Physiol 84:405-419. doi:10.1111/ j.1469-445X.1999.01810.x

32. Stanton AWB, Levick JR, Mortimer PS (1996) Evaluation of cutaneous vascular control in the arms of women with postmastectomy oedema. Exp Physiol 81:447-464

33. Roberts CC, Stanton AWB, Pullen J et al (1994) Skin microvascular architecture and perfusion studied in human postmastectomy oedema by intravital videocapillaroscopy. Int $\mathbf{J}$ Microcirc 14:327-334

34. Mellor RH, Stanton AWB, Menadue L et al (2002) Evidence for dermal angiogenesis in breast cancer related lymphoedema demonstrated using dual-site fluorescence angiography. Microcirculation 9:207-219. doi:10.1080/713774069

35. Jila A, Kim H, Nguyen VPKH et al (2007) Lymphangiogenesis following obstruction of large postnodal lymphatics in sheep. Microvasc Res 73:214-223. doi:10.1016/j.mvr.2006.11.003

36. Bates DO, Levick JR, Mortimer PS (1992) Subcutaneous interstitial fluid pressure and arm volume in lymphoedema. Int $\mathbf{J}$ Microcirc 11:359-373

37. Bates DO, Levick JR, Mortimer PS (1994) Starling pressures in the human arm and their alteration in postmastectomy oedema. J Physiol 477:355-363 